\title{
The role of coordination costs in mode choice decisions: A case study of German cities
}

\author{
Patrick Jochem ${ }^{1,2 *}$, Christopher Lisson ${ }^{1}$, and Arpita Asha Khanna ${ }^{2}$ \\ ${ }^{1}$ Karlsruhe Service Research Institute (KSRI) at Karlsruhe Institute of Technology (KIT), Kaiserstr. 89, \\ Building 05.20, D-76133 Karlsruhe, Germany \\ ${ }^{2}$ German Aerospace Center (DLR), Institute of Networked Energy Systems, Energy Systems Analysis, \\ Curiestraße 4, D-70563 Stuttgart, Germany \\ * corresponding author: jochem@kit.edu, +497116862687 \\ VERSION: March 29, 2021
}

\begin{abstract}
In times of accelerating urbanization and environmental pollution, mode choice decisions (MCD) are a critical parameter in a city's appearance and its environmental impacts. Simultaneously, the emerging smartphone multimodal traveller information systems (SMTIS) simplifies the usage of multimodal trips and, therefore, enhance the options in MCD. Current MCD models, in addition to considering classic parameters like travel time and cost, also consider socioeconomic variables and latent variables, such as modal preferences or mode-specific characteristics. However, from the users' perspective, one main influence is currently still not sufficiently considered in these models: Coordination costs for planning the trip, such as looking-up time tables for public transport. Consequently, we introduced this variable in a multinomial logit model and made a representative survey in Germany for measuring the coordination effort and evaluating our model. Our results support our hypothesis that coordination costs have a significant impact on MCD. We therefore conclude that further developments in information systems together with supporting policies may influence the MCD and, hence lead to more sustainable cities in the future.

Keywords: Mode choice decision, Mode choice, Behavior, Discrete choice, Coordination costs, Information systems
\end{abstract}




\section{Introduction}

At present, $55 \%$ of the world's population lives in urban areas and the share is still increasing (Worldbank, 2018). With their daily mobility decisions, especially with regard to their transportation mode, the inhabitants have a significant impact on their urban environment (Stradling et al., 2000, Hensher et al., 2013). In the short term, while mobility decisions influence the level of congestion, in the long term they impact common health by determining the city's mobility architecture, such as the "car-centric" Los Angeles or the "bike-centric" Copenhagen (Gehl, 2013, Abou-Zeid and Ben-Akiva, 2012). Furthermore, considering that today $18 \%$ of global $\mathrm{CO}_{2}$ emissions causing climate change stem from street-related traffic (IEA, 2018) and its share is continuously increasing (Creutzig et al., 2015) peoples' mode choice behavior has become decisive for the mobility transition.

In the classic literature on mode choice decisions (MCD) quantitative variables like travel time, cost (Ortúzar and Willumsen, 2011, Kramers, 2014, Ben-Akiva et al., 2015) and the decision maker's socioeconomic characteristics are seen as the principal determinants of MCD (?). BenAkiva and Lerman (1985) has indicated that so far unobserved factors such as travel information influences MCD. These factors can stem from psychology-related unobserved user-specific factors as well as technology-related mode-specific heterogeneity. This ambiguity motivates us to identify and investigate additional explanatory factors, which can be quantified and integrated into MCD models in order to improve their predictive power (Ben-Akiva et al., 2015).

Today, ubiquitous web access via smartphones induce a development, in which information and transportation systems have become increasingly interrelated and interdependent (Sussman, 2005). As a result, a diverse set of smartphone multimodal traveler information systems (SMTIS) have emerged (Priemus et al., 2001). These SMTIS help to extend humans' bounded rationality by enabling information-rich and complex calculations related to MCD (Ben-Elia et al., 2013, Ben-Elia and Avineri, 2015). Hence, they facilitate the coordination effort of multimodal trips, 
as well as the related transactions and travel activities (Lisson et al., 2016, 2017). Some services in this field are: mapping and navigation services (e.g. GoogleMaps), car-sharing services (e.g. SHARE NOW), route-planning services (e.g. Moovel or Qixxit), ride-sharing services (e.g. Uber or BlaBlaCar), location-based service (e.g. ParkNow), and public transportation services (e.g. the app of the local transport association or overarching aggregating services).

In this research environment the question arises of how can the simplification of multimodal trips be considered in MCD analysis. As first steps into this research area, two research questions (RQ) arise:

- RQ1: How significant is the influence of habits (i.e., individual mobility type) on MCD?

- RQ2: Do mode-specific coordination costs have an impact on the MCD and how can we integrate them into conventional MCD models?

In order to address these questions, we start from the current status of MCD modelling, i.e. we use a standard multinomial logit (MNL) model for MCD and compare its results with our extended model, which considers coordination costs, too. As the main data source, our study is based on a self-conducted online survey of 732 German traffic participants. We, therewith, identify the significance of coordination costs for German urban citizens. Finally, further research is motivated, which may use our results for analysing the concrete effects of SMTIS on (coordination costs and) MCD.

This paper is structured as follows. While Section 2 summarizes relevant related work and Section 3 explains the extended model, Section 4 introduces the empirical data. Section 5 starts with a classification of survey participants in mobility types and provides the results for all applied models. Subsequently, the results are discussed and RQ are answered in Section 6, before Section 7 concludes our findings. 


\section{Related work and background}

The research field of MCD already exhibits an extensive and established body of research. Especially, the identification of how individual habits or mobility types have an influence on the MCD is widely analysed (Triandis, 1977, Ben-Akiva and Lerman, 1985, Verplanken et al., 1997, Ramos et al., 2020) along with the identification of mobility types that reduce unobserved individuals' heterogeneity (Diana and Mokhtarian, 2009, Ben-Akiva et al., 2015, Gärling and Axhausen, 2003) The research on MCD has nonetheless dynamically evolved during the last decades by including insights that were previously hard to achieve, e.g. due to technical restrictions and missing information (Kenyon and Lyons, 2003, Chorus, Molin and Van Wee, 2006, Priemus et al., 2001).

Continuous observations of real-world MCD via smartphones and the influence of intelligent SMTIS on MCD has revolutionized the data availability in this field (Zhao et al., 2015, Kramers, 2014, Adler and Blue, 1998, Cottrill et al., 2013). Against this context, our research questions build upon the following: established economic theories in the transportation domain (Ben-Akiva and Lerman, 1985) and the recent findings in behavioral economics related to SMTIS and its influence on MCD (Ben-Elia and Avineri, 2015, Gan and Ye, 2018). Therein utility functions are considered key for investigating the factors influencing MCD, as they operationalize the complex decision on mode choices at different occasions and thus represent individuals' (subjective) preferences over the available transportation modes (Ben-Akiva and Lerman, 1985).

In economic theory, it is still assumed that individuals attempt to select transportation modes with the highest perceived utility (Train, 1980), which not only considers economic (Ben-Akiva et al., 2015) aspects but also accounts for behavior-related ones (Ben-Elia and Avineri, 2015, Hensher et al., 2013, Vij et al., 2013). Driven by a higher diversity of available transportation modes and services, intermodal urban transport networks are becoming more complex and interrelated (Nuzzolo and Lam, 2017, Sussman, 2005). This makes it practically impossible or at least cognitively difficult to gather all the information that is required for a sophisticated route choice or 
MCD (Ben-Elia et al., 2008). This leads to uncertainties in MCD and might lead to an inefficient allocation of mobility resources (Kahneman and Egan, 2011, Ben-Elia and Avineri, 2015). The lack of knowledge predominantly exists along two dimensions (Bonsall, 2004, Chorus, Arentze, Molin, Timmermans and Van Wee, 2006). First, travelers may not know all available and feasible travel alternatives, regarding mode-route combinations that may bring them to their destination (Ramming, 2002, Hoogendoorn-Lanser and Van Nes, 2004). And second, of the alternatives they do know, they may not be aware of their precise attributes concerning travel times, costs and other relevant factors (Ouwersloot et al., 1997, Avineri and Prashker, 2003, Bates et al., 2001).

Researchers have acknowledged this problem and have called for a deeper investigation into how "cognitive effort" or "mental effort" is caused by humans' bounded rationality (Simon, 1956, 1997) in a complex transportation environment (Sussman, 2005, Kramers, 2014) and how its consideration can improve the prediction of MCD (Gao et al., 2011, Grotenhuis et al., 2007, Hensher et al., 2013, Ben-Elia and Avineri, 2015). Such a consideration of limited information processing capabilities in decisions is an established approach in the Information Systems domain (Malone et al., 1987, Bakos and Brynjolfsson, 1998). Therein, the phenomenon of coordination costs is defined as the costs of gathering information, evaluating alternative options, negotiating, contracting, and physically transacting an object (Williamson, 1989, 1981). These costs result from the complexity and uncertainty of the particular system. Malone et al. (1987) formalized these "coordination cost" and incorporated them into utility functions in the context of electronic markets. In the MCD context, coordination effort represents the required cognitive effort to conduct a trip of a certain distance from origin to destination with a particular transportation mode.

Reverting to findings in the Information Systems domain, where e.g. Malone et al. (1987) exemplified the explanatory power of coordination costs in transaction cost economics, transportation researchers have hypothesized that coordination effort, such as cognitive costs and mental effort, would have an effect on MCD, too (Grotenhuis et al., 2007, Hensher et al., 2013, Ben-Elia and Avineri, 2015). They saw technical support in the form of SMTIS and its predecessor, like 
intelligent traveller information systems (Adler and Blue, 1998) or advanced traveller information systems (Kenyon and Lyons, 2003, Polydoropoulou, 1997), as a possibility to address that problem (Kramers, 2014). This relates to such systems' data processing capability and their provision of personalized travel information, which can positively influence the MCD in these complex environments (Abdel-Aty et al., 1997, Chorus, Molin and Van Wee, 2006, Lisson et al., 2016). Thereby, researchers have found that SMTIS reduces mobility-related complexity by an intelligent use of information systems that coordinate individual user preferences with appendant resources of transportation modes (Ben-Elia and Avineri, 2015, Lisson et al., 2017, Kenyon and Lyons, 2003, Vij et al., 2013). Furthermore, the provision of an adequate travel information is expected to decrease the uncertainty of mobility options and thereby assist travelers in making better choices given the uncertain and complex multimodal travel networks (Walker and Ben-Akiva, 1996, Adler and Blue, 1998, Ben-Elia and Avineri, 2015). Tying up with the preceding work, we hypothesize that, ceteris paribus, higher mode-related coordination effort would have a negative effect on the likelihood of a particular transportation mode to be chosen.

Our contribution in the field of current MCD modelling is to integrate mode-specific coordination costs in MNL models and show its significance for an urban German case study by applying a comprehensive statistical model.

\section{Extending the current MCD modelling by considering coordination costs}

In order to improve the current MCD modelling, we first introduce a classical MNL model which includes, in addition to the usual variables, mobility types, which are identified by implementing a two-stage clustering approach (cf. Section 3.1, where the focus is on RQ1). Second, we show the extension of the existing MNL model by integrating coordination costs into them (cf. Section 3.2, where the focus is on RQ2). 


\subsection{Identifying mobility types by clustering}

It is undeniable that humans are biased in their MCD (cf. Ben-Elia and Avineri (2015)) and show individual preferences for the different modes (Bhat, 2000). However, the way to account for this phenomenon is not yet decided in the literature. While some focus on measuring the habits directly during the MCD (cf. the Self-Report Habit Index (SRHI) as developed by Verplanken and Orbell (2003) and applied by Gardner et al. (2012) or Gutiérrez et al. (2020)), others prefer to either apply statistical approaches which consider further latent and attitudinal information in mode choice models (e.g. Habib and Zaman (2012)) or conduct a cluster analysis. As this issue of mobility types is not our core task, we chose the cluster analysis approach. For considering habits on mode and route choice decisions, as identified by Triandis (1977), Ben-Akiva and Lerman (1985), Lanken et al. (1994), and for identifying mobility types that reduce unobserved individuals' heterogeneity (Diana and Mokhtarian, 2009, Ben-Akiva et al., 2015, Gärling and Axhausen, 2003) we apply a two-stage clustering approach.

Our two-stage process aligns to the one conducted by Diana (2010) and is extended with more sophisticated data analysis methods used by Bishop (2006) and Witten et al. (2016). The clustering aims at maximizing the distance (i.e. dissimilarity) between groups while simultaneously minimizing the distance within a group. To compute the distance between two objects, we use squared Euclidean distance metric - which is the sum of the squared differences in values for each variable. The squared Euclidean distance between two points, $\mathrm{x}$ and $\mathrm{y}$, is given in Equation 1.

$$
d^{2}(x, y)=\sum_{i=1}^{n}\left(x_{i}-y_{i}\right)^{2}
$$

We use a hierarchical clustering procedure, the Ward's method, to identify the structure in the data and generate cluster centers. Subsequently, we use those cluster centers as the starting point for a more robust non-hierarchical (K-means) clustering procedure (Ward Jr, 1963, Kaufman and 
Rousseeuw, 2009).

In order to cluster individuals into different mobility types, we use a set of multiple variables as the clustering criteria. These include the typical usage frequency of the following transportation modes: bicycle, car (as a driver), car (as a passenger), walking, public transport, long distance train or bus, and combination of different transport modes.

\subsection{Extending the multinomial logit model for considering coordination costs}

For testing the influence of coordination effort on MCD, we estimate a MNL model (cf. Chapter 4). These models are built on individual utility maximization framework which is consistent with random utility theory. According to random utility theory, an individual $i$ facing $J$ modes will choose a mode that maximizes his or her utility. The utility function, $U$, for the individual $i$ choosing the $j$ mode is given as follows:

$$
U_{i j}=V_{i j}+e_{i j}
$$

where $V$ represents the deterministic part of the utility function, which depends on regressors and unknown parameters. $e$ is the standard extreme-value distributed error term. Based on this, the MNL model that we estimate is given below:

$$
\operatorname{Prob}_{i j}=\frac{e^{V_{i j}}}{\sum_{k=1}^{J} e^{V_{i k}}}
$$

where

$$
V_{i j}=\theta_{j}+\beta \cdot X_{i j}^{\prime}+\alpha_{j} \cdot Z_{i}^{\prime}
$$

$X$ is the vector of mode-specific variables which vary with individuals and modes. $Z$ is the 
vector of individual-specific variables which vary only with individuals and not with modes. $\theta$ are alternative-specific intercepts. $\beta$ are coefficients for mode-specific variables, while $\alpha$ are coefficients for individual-specific variables. We first estimate the standard MCD model wherein we include variables which have been identified as important in influencing MCD. These include, as discussed in Section 2, mode-specific variables like travel time and travel cost, and individual-specific variables like mobility types and socio-economic characteristics of people.

We then extend the model and include mode-specific coordination effort.

$$
V_{i j}=\theta_{j}+\beta \cdot X_{i j}^{\prime}+\alpha_{j} \cdot Z_{i}^{\prime}+\gamma \cdot \operatorname{coord}_{i j}^{\prime}
$$

where coord refers to coordination effort. $\gamma$ is our main coefficient of interest. We expect $\gamma$ to be negative - that is, increase in coordination effort for one mode should decrease the demand for that mode and increase the demand for the other modes.

\section{Empirical data}

Having introduced our model, this section deals with data gathering (cf. Section 4.1), the description of socio-demographic information on the survey participants (cf. Section 4.2), and their stated mode-specific coordination efforts (cf. Section 4.3).

\subsection{Data gathering}

For evaluating the research model, a questionnaire-based study was conducted in 2017 following the guidelines by Krosnick (2018) and Groves et al. (2011). The target population comprises of a representative share of the entire population of major German urban areas. We assumed that the larger the city, the more mobility options are available and, consequently, the larger the portfolio of SMTIS. We therefore selected four out of the six largest cities in Germany which provide besides a very diversified public transportation system including among others metro, tramway, 
and buses also several SMTIS opportunities such as car-sharing and advanced mobility information systems. The selected cities are: Berlin (3.7 million inhabitants), Hamburg (1.8), Munich (1.5), and Stuttgart (0.6).

The survey is composed of three thematic blocks: First, general questions on the modal choice are asked. Second, specific questions on the everyday mode choice for commuting (habitual decision) as well as for seldom leisure trips (new decision) follow, before, third, user-specific attributes are focused on (cf. Appendix D). The average time of completion has been 13 minutes. All completions under 5 minutes and over 50 minutes have been excluded due to data cleansing related to "rushing" and "satisficing" (Groves et al., 2011). The survey was conducted online in June 2017 using Survey-Monkey. The representative subject pools have been acquired over two distinct marketing agencies. Thereby 732 people were approached to participate and 657 sustained after omitting the answers not given within the time constraint.

\subsection{Socio-demographics}

The sample's key socio-demographic characteristics are described by gender, income, and age. With regard to gender, the distribution in the sample with $53.8 \%$ female to $46.2 \%$ male participants is slightly skewed in favor of female ones. The distribution with regard to income and age resembles those of the empirical population (cf. Figure Appendix.1 and Appendix.2) and other surveys (cf. Jamal and Habib (2019) and Chlond et al. (2013)). This, together with the distribution of SMITS usage, is shown in Table 1.

\subsection{Mode-specific coordination effort}

In the survey all participants reported the coordination effort in minutes that they perceived when coordinating a trip with a particular transportation mode. The results indicate the following average coordination effort across different modes: walking (3.53 min.), bicycle (4.86 min.), car as a driver (6.95 min.), public transport (7.95 min.), combination of different transports (8.30 min.), car as a passenger (10.17 min.), and long-distance trains and buses (11.97 min.). Evidently the 


\begin{tabular}{cc|cc|cc}
\hline \multicolumn{2}{c}{ Income } & \multicolumn{2}{c}{ Age } & \multicolumn{2}{c}{ SMITS usage } \\
In Euro & Distribution & In years & Distribution & Frequency & Distribution \\
\hline 1000 and less & $13.2 \%$ & 20 and less & $3.8 \%$ & Seldom or never & $2.4 \%$ \\
$1001-2000$ & $27.0 \%$ & $20-29$ & $21.8 \%$ & $1-3$ times per year & $6.4 \%$ \\
$2001-3000$ & $29.1 \%$ & $30-39$ & $25.5 \%$ & $1-3$ times per month & $23.3 \%$ \\
$3001-4000$ & $17.9 \%$ & $40-49$ & $20.6 \%$ & $1-3$ times per week & $21.6 \%$ \\
$4001-5000$ & $6.4 \%$ & $50-59$ & $17.5 \%$ & $4-6$ times per week & $20.8 \%$ \\
5001 and more & $6.5 \%$ & $60-69$ & $8.5 \%$ & Once per day & \\
& & 70 and above & $2.2 \%$ & or more often & $25.6 \%$ \\
\hline
\end{tabular}

Table 1: Distribution of main user characteristics

transportation modes which are under an individual's full control - that is, under its ownership - such as the feet, bicycle and individual car exhibit a lower level of average coordination effort compared to the modes that are used by multiple people and are not owned and controlled by a single person. This seems reasonable since pooling requires additional coordination effort to match multiple entities' needs and interest on a limited set of resources such as public transportation.

\section{Application of the extended model}

In the following, we estimate the models introduced in Section 3.2 in order to gain deeper insights into the factors that drive MCD. The following section presents the results for mobility types that are identified through cluster analysis (cf. Section 3.1). Section 5.2 presents the results from the extended MNL model (cf. Section 3.2). Section 5.3 gives robustness checks.

\subsection{Identification of mobility types through cluster analysis}

As mentioned in Section 3.1, we use mode-specific frequency of usage as the variable to cluster the survey participants. The application of Ward's linkage method gives us a three-group clustering solution. The corresponding statistics and information (Cluster dendrogram, Duda-Hart index, pseudo T-squared values, and Calinksi-Harabasz pseudo-F values) are provided in Appendix B. We then apply a K-means clustering method, pre-specifying the number of clusters to be three. The results across both the Ward's linkage and K-means clustering methods remain mostly stable. 


\begin{tabular}{c|ccccccc}
\hline Cluster & bicycle & cardrive & car-passenger & multi modal & foot & public trans. & train or bus \\
\hline 1 & 1.53 & 1.41 & 0.95 & 1.72 & $\mathbf{3 . 4 4}$ & $\mathbf{3 . 1 3}$ & 0.89 \\
2 & 0.57 & 0.18 & 0.21 & 0.20 & 0.53 & $\mathbf{1 . 3 2}$ & 0.05 \\
3 & 0.34 & $\mathbf{3 . 4 3}$ & 0.26 & 0.08 & 0.24 & 0.29 & 0.05 \\
\hline Total share & 0.81 & 1.53 & 0.46 & 0.65 & 1.39 & 1.60 & 0.32 \\
\hline
\end{tabular}

Table 2: Comparison of average frequency of usage across the three clusters

Table 2 presents the mean value of respondents in each cluster across the seven clustering variables. The results suggest that the three clusters can be interpreted as follows:

- Cluster 1 represents people who use walking and public transportation as the main modes of transportation. The cluster accounts for $32.3 \%$ of the overall sample.

- Cluster 2 represents people who mostly rely on public transportation. It accounts for $38.5 \%$ of the overall sample.

- Cluster 3 represents people who mostly drive cars. It accounts for $29.2 \%$ of the overall sample.

Accordingly, we name the three clusters as follows: "walkers and public transport lovers", "public transport lovers" and "car drivers". We assign dummies to these groups and use them in the model estimation.

\subsection{Results from the extended MNL model estimation}

By applying the maximum likelihood estimation method, we first estimate the classical MNL model that is used in the existing literature and analyze the MCD of people while going to work. Herein, we could not analyze the following modes due to limited observations: long distance train and buses $(\mathrm{N}=2)$, car as a passenger $(\mathrm{N}=14)$, and intermodal trips $(\mathrm{N}=38)$. We therefore focus on: bicycle, walking, public transport, and car driving. In the model, we include travel time, travel cost, mobility types (as identified in Section 5.1), and socio-economic characteristics of people like 


\begin{tabular}{|c|c|}
\hline Variable & Description \\
\hline Age & $\begin{array}{l}\text { individual-specific variable with: } 1 \text { (<20 years); } 2(20-29) ; 3(30-39) \text {; } \\
4(40-49) ; 5(50-59) ; 6(60-69) ; 7 \text { (> } 69 \text { years }) .\end{array}$ \\
\hline Income & $\begin{array}{l}\text { individual-specific variable with: } 1(<€ 1,000) ; 2(€ 1,001-2,000) ; 3 \\
(€ 2,001-3,000) ; 4(€ 3,001-4,000) ; 5(€ 4,001-5,000) ; 6(>€ 5,001) .\end{array}$ \\
\hline Gender & individual-specific dummy variable with "1" for male. \\
\hline Mobility type & $\begin{array}{l}\text { individual-specific dummy variable representing three types of mobil- } \\
\text { ity types obtained from cluster analysis: walkers and public transport } \\
\text { lovers, public transport lovers, and car drivers. }\end{array}$ \\
\hline Travel time & $\begin{array}{l}\text { mode-specific variable derived from commuting distance and mode- } \\
\text { specific velocity factors obtained from (Ahrens et al., 2014). }\end{array}$ \\
\hline Travel cost & $\begin{array}{l}\text { mode-specific variable derived as a product of commuting distance } \\
\text { and mode-specific cost factors }(€ / \mathrm{km}) \text { (Hütter, 2013). }\end{array}$ \\
\hline Coordination effort & $\begin{array}{l}\text { mode-specific variable with: } 1 \text { (<1 } \min ) ; 2(1-2 \mathrm{mins}) ; 3 \text { (3-5 mins); } \\
4 \text { (6-10 mins); } 5 \text { (11-15 mins); } 6 \text { (> }>16 \text { mins })\end{array}$ \\
\hline Family size & $\begin{array}{l}\text { individual-specific variable with : } 1 \text { (1 person); } 2(2-3) ; 3(4-5) ; 4 \text { (> } \\
6 \text { people). }\end{array}$ \\
\hline Education & $\begin{array}{l}\text { individual-specific variable with: } 1 \text { (Hauptschule, CSE); } 2 \text { (Mittlere } \\
\text { Reife, GCSE); } 3 \text { (Abitur, A levels); } 4 \text { (Hochschulabschluss, university } \\
\text { degree). }\end{array}$ \\
\hline Employment & individual-specific dummy variable with "1" for employed. \\
\hline Location of residence & $\begin{array}{l}\text { individual-specific categorical variable representing the following: big } \\
\text { city, countryside, suburbs, small city, and medium city. }\end{array}$ \\
\hline $\begin{array}{l}\text { Time to pub trans. } \\
\text { from residence }\end{array}$ & $\begin{array}{l}\text { individual-specific variable representing how long does it take to get } \\
\text { to the nearest public transport connection on foot from the place of } \\
\text { residence: } 1(<1 \mathrm{~min}) ; 2(2-5) ; 3(6-10) ; 4(11-15) ; 5(>16) \text {. }\end{array}$ \\
\hline $\begin{array}{l}\text { Time to pub trans. } \\
\text { from work }\end{array}$ & $\begin{array}{l}\text { individual-specific variable representing how long does it take to get } \\
\text { to the nearest public transport connection on foot from the place of } \\
\text { "work": } 1(<1 \mathrm{~min}) ; 2(2-5) ; 3(6-10) ; 4(11-15) ; 5(>16) \text {. }\end{array}$ \\
\hline $\begin{array}{l}\text { Freq. of pub trans. } \\
\text { connections }\end{array}$ & $\begin{array}{l}\text { individual-specific variable with: } 1 \text { (less than once in an hour); } 2 \\
(41-60) ; 3(21-40) ; 4(11-20) ; 5(3-10) ; 6(<2 \mathrm{~min}) \text {. }\end{array}$ \\
\hline Difficulty in parking & $\begin{array}{l}\text { individual-specific dummy variable with "1" for the parking being } \\
\text { difficult. }\end{array}$ \\
\hline Ownership of car & individual-specific dummy variable with "1" if individuals own a car. \\
\hline
\end{tabular}

Table 3: Description of variables 


\begin{tabular}{l|cccc}
\hline Variable & Mean & Std. Dev. & Min & Max \\
\hline Age & 4.03 & 1.54 & 1 & 7 \\
Income & 3.05 & 1.32 & 1 & 6 \\
Travel time & 1.44 & 1.7 & 0.02 & 8.16 \\
Travel cost & 1.29 & 1.63 & 0 & 7.22 \\
Coordination effort & 3.14 & 1.87 & 1 & 6 \\
Family size & 1.84 & 0.70 & 1 & 4 \\
Education & 2.70 & 1.03 & 1 & 4 \\
Time to pub trans. from residence & 2.32 & 0.84 & 1 & 5 \\
Time to pub trans. from work & 2.51 & 0.99 & 1 & 5 \\
Freq. of pub trans. Connections & 4.30 & 1.08 & 1 & 6 \\
\hline
\end{tabular}

Table 4: Descriptive statistics for the metric variables

The results are presented in Table 5. We take car driving as the base outcome. The results show that income and mobility types are important determinants of MCD. All else equal, the individuals with high income will prefer to drive cars over using a bicycle and public transportation. Similarly, car lovers will prefer to drive cars as compared to using other modes. Among modespecific variables, travel time has a significantly negative effect on MCD. Higher travel time for a particular mode would decrease the demand for that mode and increase the demand for the other modes. These results are in line with the literature which suggests that travel time, habits, and socio-economic characteristics of individuals are robust determinants of MCD (e.g. Lanken et al. (1994), Ortúzar and Willumsen (2011), and Ben-Akiva et al. (2015)). 


\begin{tabular}{|c|c|c|c|c|}
\hline Variable & Modes & Bicycle & Walking & Pub.Trans. \\
\hline \multirow[t]{2}{*}{ Age } & & -0.0831 & 0.0251 & 0.0898 \\
\hline & & $(0.164)$ & $(0.215)$ & $(0.156)$ \\
\hline \multirow[t]{2}{*}{ Income } & & $-0.540 * * *$ & -0.392 & $-0.607 * * *$ \\
\hline & & $(0.207)$ & $(0.261)$ & $(0.177)$ \\
\hline \multirow[t]{2}{*}{ Gender } & & 0.254 & -0.489 & -0.598 \\
\hline & & $(0.515)$ & $(0.636)$ & $(0.461)$ \\
\hline \multirow[t]{2}{*}{ Pub trans. lovers } & & $1.375^{* *}$ & -0.0812 & 0.333 \\
\hline & & $(0.654)$ & $(0.735)$ & $(0.580)$ \\
\hline \multirow[t]{2}{*}{ Car lovers } & & $-4.079 * * *$ & $-20.96 * * *$ & $-6.449 * * *$ \\
\hline & & $(0.756)$ & $(0.805)$ & $(0.726)$ \\
\hline Travel time & $\begin{array}{c}-4.587^{* * *} \\
(0.883)\end{array}$ & & & \\
\hline \multirow[t]{2}{*}{ Travel cost } & -0.513 & & & \\
\hline & $(0.323)$ & & & \\
\hline \multirow[t]{2}{*}{ Constant } & & $3.637^{* * *}$ & $6.888^{* * *}$ & $5.385^{* * *}$ \\
\hline & & $(1.337)$ & $(1.437)$ & $(1.167)$ \\
\hline Observations & 1816 & 1816 & 1816 & 1816 \\
\hline Log likelihood & -252.84 & -252.84 & -252.84 & -252.84 \\
\hline No. of individuals & 454 & 454 & 454 & 454 \\
\hline
\end{tabular}

Note: Dependent variable is the means of transport that people use to get to their place of work/training/university or school. Multinomial logit model is used. Base outcome is car driving. Robust standard errors are reported in parentheses. ${ }^{*}, * *, * * *$ represent that the estimates are significant at $10 \%, 5 \%$ and $1 \%$ levels of significance respectively.

Table 5: Mode choice decisions while going to work

We now estimate the model which also includes coordination effort - our main variable of interest. The results of the extended model are presented in Table 6. The results support our hypothesis. Coordination effort has a negative effect on MCD and this effect is significant at 1\% demand for that mode and increase the demand for the other modes. 


\begin{tabular}{|c|c|c|c|c|}
\hline Variable & Modes & Bicycle & Walking & Pub.Trans. \\
\hline Age & & $\begin{array}{c}-0.201 \\
(0.188)\end{array}$ & $\begin{array}{l}-0.326 \\
(0.259)\end{array}$ & $\begin{array}{c}0.0154 \\
(0.170)\end{array}$ \\
\hline Income & & $\begin{array}{c}-0.607^{* * *} \\
(0.234)\end{array}$ & $\begin{array}{l}-0.360 \\
(0.280)\end{array}$ & $\begin{array}{c}-0.571^{* * *} \\
(0.197)\end{array}$ \\
\hline Gender & & $\begin{array}{c}0.154 \\
(0.587)\end{array}$ & $\begin{array}{l}-0.106 \\
(0.738)\end{array}$ & $\begin{array}{l}-0.711 \\
(0.553)\end{array}$ \\
\hline Pub trans. lovers & & $\begin{array}{c}2.344^{* * *} \\
(0.889)\end{array}$ & $\begin{array}{c}0.749 \\
(0.970)\end{array}$ & $\begin{array}{c}1.231 \\
(0.824)\end{array}$ \\
\hline Car lovers & & $\begin{array}{c}-2.960 * * * \\
(0.777)\end{array}$ & $\begin{array}{c}-19.15^{* * *} \\
(0.941)\end{array}$ & $\begin{array}{c}-5.286^{* * *} \\
(0.729)\end{array}$ \\
\hline Travel time & $\begin{array}{c}-4.010^{* * *} \\
(0.903)\end{array}$ & & & \\
\hline Travel cost & $\begin{array}{c}-0.605^{*} \\
(0.329)\end{array}$ & & & \\
\hline Coordination effort & $\begin{array}{c}-0.448 * * * \\
(0.143)\end{array}$ & & & \\
\hline Constant & & $\begin{array}{c}3.791^{* * *} \\
(1.304)\end{array}$ & $\begin{array}{c}6.770^{* * *} \\
(1.426)\end{array}$ & $\begin{array}{c}5.079 * * * \\
(1.145)\end{array}$ \\
\hline Observations & 1151 & 1151 & 1151 & 1151 \\
\hline Log likelihood & -184.99 & -184.99 & -184.99 & -184.99 \\
\hline No. of individuals & 360 & 360 & 360 & 360 \\
\hline
\end{tabular}

Note: Dependent variable is the means of transport that people use to get to their place of work/training/university or school. Multinomial logit model is used. Base outcome is car driving. Robust standard errors are reported in parentheses. *, **, *** represent that the estimates are significant at 10\%, $5 \%$ and $1 \%$ levels of significance respectively.

Table 6: Mode choice decisions while going to work (including coordination effort)

To put the results in perspective we compute the marginal probability effects at the mean value of explanatory variables. The results are presented in Table 7 . The results suggest that a one point decrease in coordination effort for public transportation will increase the probability of using public transportation by around 9 percentage points, and reduce the probability of car driving by around 2 percentage points. Similarly, a one point decrease in coordination effort for bicycle and walking will increase the probability of using the respective modes by 6.6 and 1.4 percentage points. The corresponding decrease in car driving would be 0.4 and 0.1 percentage points respectively. 


\begin{tabular}{c|cccc}
\hline$\frac{4}{4(\text { prob. })}$ & \multicolumn{3}{|c}{ Probability of using different modes } \\
\hline$d($ coord.eff. $)$ & Bicycle & Walking & Public trans. & Car driving \\
\hline Bicycle & .066 & -.003 & -.059 & -.004 \\
Walking & -.003 & .014 & -.011 & -.001 \\
Public trans. & -.059 & -.011 & .088 & -.018 \\
Car driving & -.004 & -.001 & -.018 & .024 \\
\hline
\end{tabular}

Table 7: Marginal effects of mode-specific decreasing coordination effort by one point on mode choice decisions

\subsection{Robustness checks}

We now undertake measures to check the robustness of our results. We first check for the presence of multicollinearity which could lead to the problem of imprecise estimation. Table C1 in Appendix shows that the correlation among variables is low, suggesting that multicollinearity is not a concern. We include other socio-economic variables in the model and test if the results for coordination effort remain consistent. These include the level of education, employment status, and family size. The results, as presented in Table C2 in the Appendix, show that coordination effort is still a significant determinant of MCD. We also checked the robustness of results by controlling for location of residence, public transport connections and frequencies, parking situation at work, and ownership of car (see Table C3 in the Appendix). These results, as well as further regressions which are not indicated here, indicate a robust negative influence of coordination effort for all the tested models.

Until now, we have analyzed people's MCD while going to work (habitual decision). We now analyze if coordination effort influences the mode choice of people while going to new destinations (new decision, often a leisure event). We estimate a model where the dependent variable is the mode of transport that the survey participants used while going to a leisure event in the past. We include coordination effort in the model along with all the core independent variables. The results, as presented in Table $\mathrm{C} 4$ in the Appendix, show again that coordination effort has a negative effect and that the effect is significant at $1 \%$ level of significance.

The overall results suggest that coordination effort is indeed an important variable that in- 
fluences MCD and should not be neglected as has been done in the existing studies. Including coordination effort in MCD models is important for studying the mode decisions of people in a comprehensive manner.

\section{Discussion and implications}

With the results at hand this section discusses the implications. We structure this section according to the two research questions from Section 1.

\subsection{RQ1: How significant is the influence of habits (i.e., individual mobility type) on MCD?}

While the influence of habitual behavior has often been shown to have an influence on MCD by many studies (cf. Section 2), our findings extend the literature for the case of German urban citizens. As indicated in Section 5.1, our clustering approach shows unique mobility types which can be clearly separated. In these German cities public transportation seems to play a major role as the two largest clusters include public transportation, i.e. Cluster 1, Walkers and Public Transport Lovers, and Cluster 2, Public Transport Lovers. The third cluster is dominated by car drivers. Considering the influence of these mobility types, our findings provide empirical support that the inclusion of habits represented by mobility types has a significant impact on MCD.

6.2. RQ2: Do mode-specific coordination costs have an impact on the MCD and how can we integrate them into conventional MCD models?

Our dedicated survey on coordination costs among German urban citizens (cf. Section 4) and the corresponding evaluation of the MNL model (cf. Section 5.2) showed that there is a modedependent negative influence of coordination costs on the MCD. The strong elasticity (i.e. a one point decrease in coordination effort for public transportation increases the probability of using public transportation by around nine percentage points) is providing a significant leverage for policymakers to focus on measures for reducing coordination costs of environmentally friendly modes, such as public transport. This insight contributes to the current challenges of the car-congested 
urban environments and the ongoing discussions in the literature since it supports the hypothesis derived from studies by previous researchers (cf. Section 2).

By affirming RQ2 and as SMTIS seems to reduce and equalize all coordination costs (cf. Sections 1 and 2), we conclude that SMTIS have a substantial potential for contributing to sustainable transport systems by influencing MCD in car-dominated urban areas. This insight is in line with Polydoropoulou (1997). Policy makers may provide convincing and sustainable modes (such as a convenient public transportation system, prioritized bicycle lines, ride-sharing services, etc.) in order to accelerate this process.

\subsection{Limitations of our study and future work}

One core limitation of our study is that it is based on stated preferences and does not use empirical data of MCD. This might be an interesting subject for future research. Second, the survey is cross sectional and hence does not consider the developments over time. Furthermore, we identified a weak correlation (with only few observations for long distance trips) between coordination effort and trip distance, hence, coordination costs seem to be mode-distance-specific. Further analysis on this seems promising. Additionally, analyzing the determinants of coordination costs (e.g. SMTIS) using the empirical data from smartphones (cf. Thomas et al. (2019)) might be of interest for further research.

\section{Conclusions}

German modal split is still dominated by car trips. Most car addicted traffic participants seem to choose this mode, because of their habits. Hence, the habits have a substantial influence on our mode choices today. Until the late nineties, classical mode choice modelling focused mainly on travel costs, travel time, and socio-demographic variables. The studies since then have also operationalised the habitual mobility behaviour. 
We considered this trend in our approach and integrated mobility types in our multinomial logit based MCD model. Furthermore, we extended this approach by an additional and a very decisive factor: the coordination costs of different mode choices. With our dedicated survey of German urban citizens we established a unique basis for proving this concept. Our findings are threefold:

1. We confirmed current insights in literature by identifying habit-based mobility types for German cities, which show significantly different mode preferences.

2. We developed a method for measuring mode-specific coordination costs and integrated them into a current mode choice decision model.

3. We proved that these coordination costs have a substantial influence on the mode choice decisions in German cities.

From these findings, we conclude that SMTIS will influence mode choice decisions and may contribute significantly to more sustainable urban mobility systems. A stronger effort to implement attractive SMTIS along with the availability of convenient alternative modes, especially in cardominated regions, might accelerate our transition to a more sustainable mobility system.

\section{Acknowledgments}

We would like to thank Axel Ensslen for very helpful comments during initial phase of this work. This research was partly funded within the Ökonver project by the German Arospace Center (DLR). We do not have any declarations of interest.

\section{References}

Abdel-Aty, M. A., Kitamura, R. and Jovanis, P. P. (1997), 'Using stated preference data for studying the effect of advanced traffic information on drivers' route choice', Transportation




Abou-Zeid, M. and Ben-Akiva, M. (2012), 'Well-being and activity-based models', Transportation 39(6), 1189-1207.

Adler, J. L. and Blue, V. J. (1998), 'Toward the design of intelligent traveler information systems', Transportation Research Part C: Emerging Technologies 6(3), 157-172.

Ahrens, G.-A., Ließke, F., Wittwer, R., Hubrich, S. and Wittig, S. (2014), 'Tabellenbericht zum forschungsprojekt "mobilität in städten-srv 2013", Berlin, Germany, (in German).

Avineri, E. and Prashker, J. (2003), 'Sensitivity to uncertainty: need for a paradigm shift', Transportation Research Record (1854), 90-98.

Bakos, Y. and Brynjolfsson, E. (1998), Organizational partnerships and the virtual corporation, in C. F. Kemerer, ed., 'Information Technology and Industrial Competitiveness', Springer, Boston, MA, US, pp. 49-66.

Bates, J., Polak, J., Jones, P. and Cook, A. (2001), 'The valuation of reliability for personal travel', Transportation Research Part E: Logistics and Transportation Review 37(2-3), 191-229.

Ben-Akiva, M. E. and Lerman, S. R. (1985), Discrete choice analysis: theory and application to

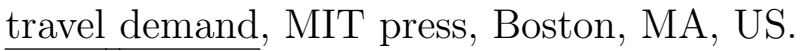

Ben-Akiva, M., McFadden, D. and Train, K. (2015), 'Foundations of stated preference elicitacion: consumer behaviour and choice-based conjoint analysis', Foundations and Trends in Econometrics 10(1-2), 1-144.

Ben-Elia, E. and Avineri, E. (2015), 'Response to travel information: A behavioural review', Transport Reviews 35(3), 352-377.

Ben-Elia, E., Di Pace, R., Bifulco, G. N. and Shiftan, Y. (2013), 'The impact of travel information's accuracy on route-choice', Transportation Research Part C: Emerging Technologies 26(1), 146159. 
Ben-Elia, E., Erev, I. and Shiftan, Y. (2008), 'The combined effect of information and experience on drivers' route-choice behavior', Transportation 35(2), 165-177.

Bhat, C. R. (2000), 'Incorporating observed and unobserved heterogeneity in urban work travel mode choice modeling', Transportation Science 34(2), 228-238.

Bishop, C. M. (2006), Pattern recognition and machine learning, Springer, New York, US.

Bonsall, P. (2004), 'Traveller behavior: Decision-making in an unpredictable world', Journal of Intelligent Transportation Systems 8(1), 45-60.

Chlond, B., Wirtz, M. and Zumkeller, D. (2013), Data quality and completeness issues in multiday or panel surveys, in J. Zmud, M. Lee-Gosselin, M. A. Munizaga and J. A. Carrasco, eds, 'Transport Survey Methods: Best Practice for Decision Making', Emerald, Brigley, UK, pp. 373-392.

Chorus, C. G., Arentze, T. A., Molin, E. J., Timmermans, H. J. and Van Wee, B. (2006), 'The value of travel information: Decision strategy-specific conceptualizations and numerical examples', Transportation Research Part B: Methodological 40(6), 504-519.

Chorus, C. G., Molin, E. J. and Van Wee, B. (2006), 'Use and effects of advanced traveller information services (atis): a review of the literature', Transport Reviews 26(2), 127-149.

Cottrill, C. D., Pereira, F. C., Zhao, F., Dias, I. F., Lim, H. B., Ben-Akiva, M. E. and Zegras, P. C. (2013), 'Future mobility survey: Experience in developing a smartphone-based travel survey in singapore', Transportation Research Record 2354(1), 59-67.

Creutzig, F., Jochem, P., Edelenbosch, O. Y., Mattauch, L., van Vuuren, D. P., McCollum, D. and Minx, J. (2015), 'Transport: A roadblock to climate change mitigation?', Science 350(6263), 911-912. 
Diana, M. (2010), 'From mode choice to modal diversion: A new behavioural paradigm and an application to the study of the demand for innovative transport services', Technological Forecasting and Social Change 77(3), 429-441.

Diana, M. and Mokhtarian, P. L. (2009), 'Grouping travelers on the basis of their different car and transit levels of use', Transportation 36(4), 455-467.

Gan, H. and Ye, X. (2018), 'Will commute drivers switch to park-and-ride under the influence of multimodal traveler information? a stated preference investigation', Transportation research part F: traffic psychology and behaviour 56, 354-361.

Gao, S., Frejinger, E. and Ben-Akiva, M. (2011), 'Cognitive cost in route choice with real-time information: An exploratory analysis', Procedia-Social and Behavioral Sciences 17, 136-149.

Gardner, B., Abraham, C., Lally, P. and de Bruijn, G.-J. (2012), 'Towards parsimony in habit measurement: Testing the convergent and predictive validity of an automaticity subscale of the self-report habit index', International Journal of Behavioral Nutrition and Physical Activity $\mathbf{9}(1), 102$.

Gärling, T. and Axhausen, K. W. (2003), 'Introduction: Habitual travel choice', Transportation $30(1), 1-11$.

Gehl, J. (2013), Cities for people, Island press, Washington D.C., US.

Grotenhuis, J.-W., Wiegmans, B. W. and Rietveld, P. (2007), 'The desired quality of integrated multimodal travel information in public transport: Customer needs for time and effort savings', Transport Policy 14(1), 27-38.

Groves, R. M., Fowler Jr, F. J., Couper, M. P., Lepkowski, J. M., Singer, E. and Tourangeau, R. (2011), Survey methodology, John Wiley \& Sons, Hoboken, NJ, US. 
Gutiérrez, M., Hurtubia, R. and Ortúzar, J. de D. (2020), 'The role of habit and the built environment in the willingness to commute by bicycle', Travel behaviour and society 20, 62-73.

Habib, K. M. N. and Zaman, M. H. (2012), 'Effects of incorporating latent and attitudinal information in mode choice models', Transportation Planning and Technology 35(5), 561-576.

Hensher, D. A., Rose, J. M., Leong, W., Tirachini, A. and Li, Z. (2013), 'Choosing public transport-incorporating richer behavioural elements in modal choice models', Transport Reviews 33(1), 92-106.

Hoogendoorn-Lanser, S. and Van Nes, R. (2004), 'Multimodal choice set composition: Analysis of reported and generated choice sets', Transportation Research Record (1898), 79-86.

Hütter, A. (2013), Verkehr auf einen Blick, Statistisches Bundesamt, Bonn, Germany, (in German).

IEA (2018), $\mathrm{CO}_{2}$ Emissions from Fuel Combustion, International Energy Agency, Paris, France.

Jamal, S. and Habib, M. A. (2019), 'Investigation of the use of smartphone applications for trip planning and travel outcomes', Transportation Planning and Technology 42(3), 227-243.

Kahneman, D. and Egan, P. (2011), Thinking fast and slow, Farrar, Straus and Giroux New York, US.

Kaufman, L. and Rousseeuw, P. J. (2009), Finding groups in data: an introduction to cluster analysis, John Wiley \& Sons, Hoboken, NJ, US.

Kenyon, S. and Lyons, G. (2003), 'The value of integrated multimodal traveller information and its potential contribution to modal change', Transportation Research Part F: Traffic Psychology and Behaviour 6(1), 1-21.

Kramers, A. (2014), 'Designing next generation multimodal traveler information systems to support sustainability-oriented decisions', Environmental Modelling \& Software 56, 83-93. 
Krosnick, J. A. (2018), Questionnaire design, in D. L. Vannette and J. A. Krosnick, eds, 'The Palgrave Handbook of Survey Research', Springer, Berlin, Germany, pp. 439-455.

Lanken, B., Aarts, H., Van Knippenberg, A. and van Knippenberg, C. (1994), 'Attitude versus general habit: Antecedents of travel mode choice', Journal of Applied Social Psychology $24(4), 285-300$.

Lisson, C., Hall, M., Michalk, W. and Weinhardt, C. (2017), What drives the usage of intelligent traveler information systems?, in G. Meyer and S. Shaheen, eds, 'Disrupting Mobility', Springer, Berlin, Germany, pp. 89-104.

Lisson, C., Roedder, N., Stroehle, P. and Weinhardt, C. (2016), Decisions in mobility service networks-coordinating demand and supply using a mechanism design approach, in 'System Sciences (HICSS), 2016 49th Hawaii International Conference on', IEEE, pp. 1606-1613.

Malone, T. W., Yates, J. and Benjamin, R. I. (1987), 'Electronic markets and electronic hierarchies', Communications of the ACM 30(6), 484-497.

Nuzzolo, A. and Lam, W. H. (2017), Introduction to modelling multimodal transit systems in an its context, in A. Nuzzolo and W. Lam, eds, 'Modelling Intelligent Multi-Modal Transit Systems', CRC Press, Boca Raton, FL, US, pp. 17-34.

Ortúzar, J. de D. and Willumsen, L. G. (2011), Modelling transport, John Wiley \& Sons, Hoboken, NJ, US.

Ouwersloot, H., Nijkamp, P. and Pepping, G. (1997), 'Advanced telematics for travel decisions: a quantitative analysis of the stopwatch project in southampton', Environment and Planning A 29(6), 1003-1016.

Polydoropoulou, A. (1997), Modeling user response to advanced travlers information systems (ATIS), PhD thesis, Massachusetts Institute of Technology. 
Priemus, H., Nijkamp, P. and Banister, D. (2001), 'Mobility and spatial dynamics: an uneasy relationship', Journal of transport geography $\mathbf{9}(3), 167-171$.

Ramming, M. S. (2002), Network Knowledge and Route Choice, Unpublished Ph. D. Thesis, Massachusetts Institute of Technology, Boston, MA, US.

Ramos, É. M. S., Bergstad, C. J. and Nässén, J. (2020), 'Understanding daily car use: Driving habits, motives, attitudes, and norms across trip purposes', Transportation research part F: traffic psychology and behaviour 68, 306-315.

Simon, H. A. (1956), 'Rational choice and the structure of the environment.', Psychological review $63(2), 129$.

Simon, H. A. (1997), Models of bounded rationality: Empirically grounded economic reason, MIT press, Boston, MA, US.

Stradling, S. G., Meadows, M. and Beatty, S. (2000), 'Helping drivers out of their cars integrating transport policy and social psychology for sustainable change', Transport Policy 7(3), 207-215.

Sussman, J. M. (2005), Intelligent transportation systems at the turning point: Preparing for integrated, regional, and market-driven deployment, in J. M. Sussman, ed., 'Perspectives on Intelligent Transportation Systems (ITS)', Springer, Boston, MA, US, pp. 173-187.

Thomas, T., Puello, L. L. P. and Geurs, K. (2019), 'Intrapersonal mode choice variation: Evidence from a four-week smartphone-based travel survey in the netherlands', Journal of Transport Geography 76, 287-300.

Train, K. (1980), 'A structured logit model of auto ownership and mode choice', The Review of Economic Studies 47(2), 357-370.

Triandis, H. C. (1977), Interpersonal behavior, Brooks/Cole Pub. Co., Pacific Grove, CA, US. 
Verplanken, B., Aarts, H. and Van Knippenberg, A. (1997), 'Habit, information acquisition, and the process of making travel mode choices', European Journal of Social Psychology 27(5), 539560.

Verplanken, B. and Orbell, S. (2003), 'Reflections on past behavior: a self-report index of habit strength', Journal of Applied Social Psychology 33(6), 1313-1330.

Vij, A., Carrel, A. and Walker, J. L. (2013), 'Incorporating the influence of latent modal preferences on travel mode choice behavior', Transportation Research Part A: Policy and Practice 54, 164178.

Walker, J. L. and Ben-Akiva, M. E. (1996), 'Consumer response to traveler information systems: laboratory simulation of information searches using multimedia technology', Journal of Intelligent Transportation Systems 3(1), 1-20.

Ward Jr, J. H. (1963), 'Hierarchical grouping to optimize an objective function', Journal of the American Statistical Association 58(301), 236-244.

Williamson, O. E. (1981), 'The economics of organization: The transaction cost approach', American Journal of Sociology 87(3), 548-577.

Williamson, O. E. (1989), 'Transaction cost economics', Handbook of industrial organization 1, 135-182.

Witten, I. H., Frank, E., Hall, M. A. and Pal, C. J. (2016), Data Mining: Practical machine learning tools and techniques, Morgan Kaufmann, Burlington, MA, US.

Worldbank (2018), The World Bank Data, Urban Development, World Bank Group, New York, US. 
Zhao, F., Pereira, F. C., Ball, R., Kim, Y., Han, Y., Zegras, C. and Ben-Akiva, M. (2015), 'Exploratory analysis of a smartphone-based travel survey in singapore', Transportation Research Record 2(2494), 45-56.

\section{Appendix A: Histograms of main user characteristics from our survey compared to} the empirical population

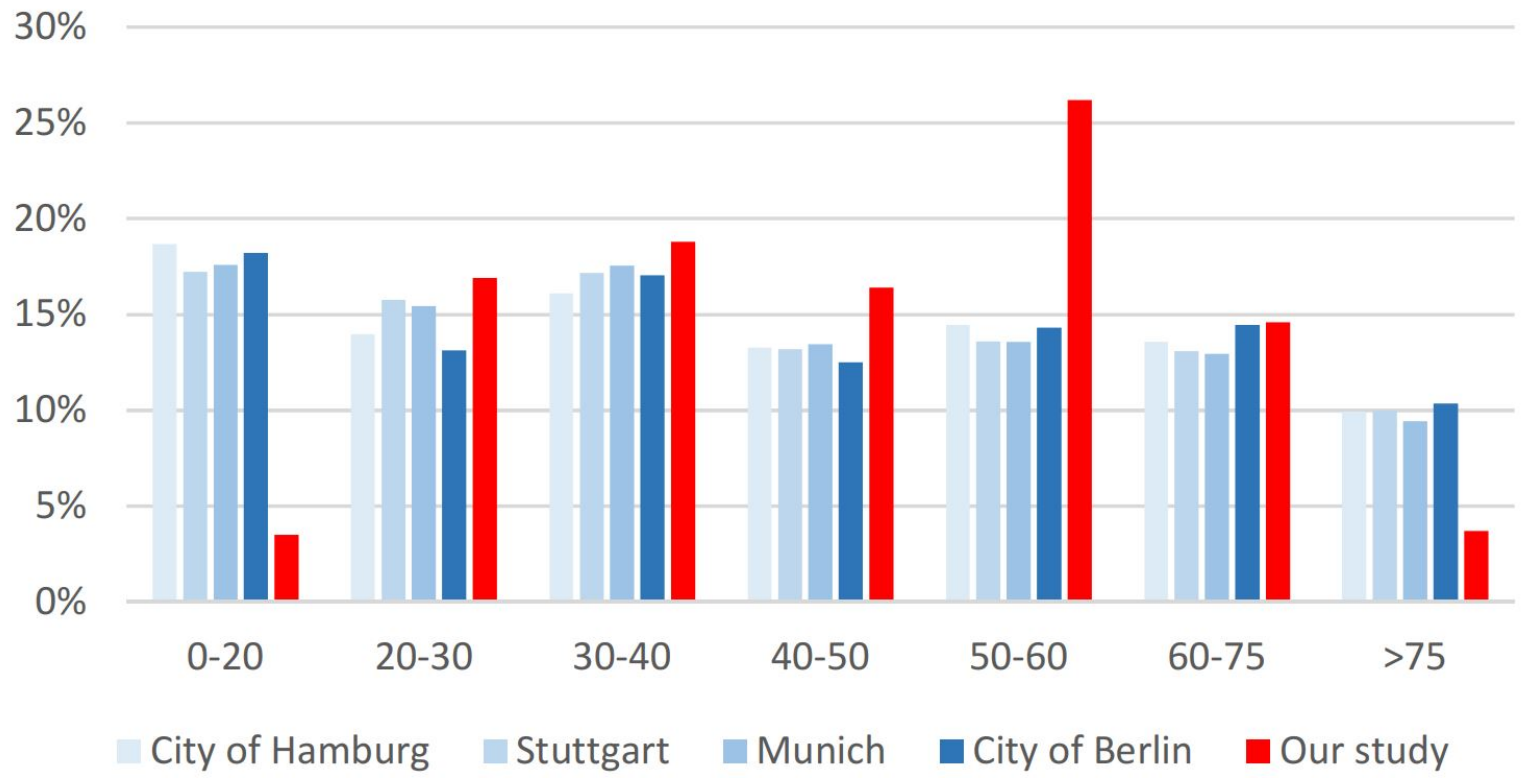

Figure Appendix.1: Histogram of the age of our survey participants compared to the empirical age in the cities considered. As we focus on the 'independent' mobile population (aged between 18 and 80) the group below 20 and above 75 is underrepresented by our data. Unfortunately, the age group of users between 50 and 60 years old is somewhat overrepresented. This impact on the overall results is, however, marginal. 


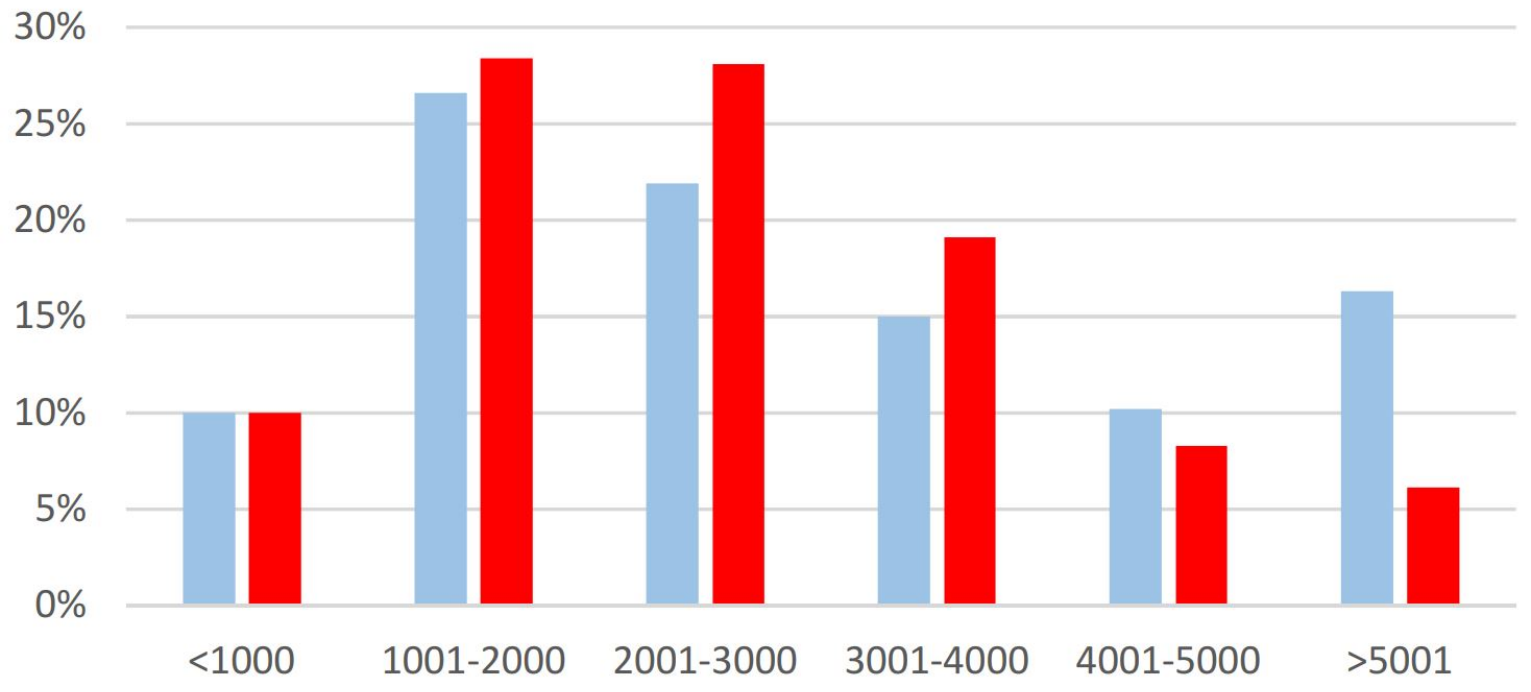

Figure Appendix.2: Histogram of the household net income (in $€$ ) of our survey participants (in red) compared to the empirical distribution for Germany (in green). People with very high income are somewhat underrepresented while the middle-income group is overrepresented. This bias seems not influencing our results significantly. There is no available data on city-level. 
Appendix B: Statistics of the cluster analysis

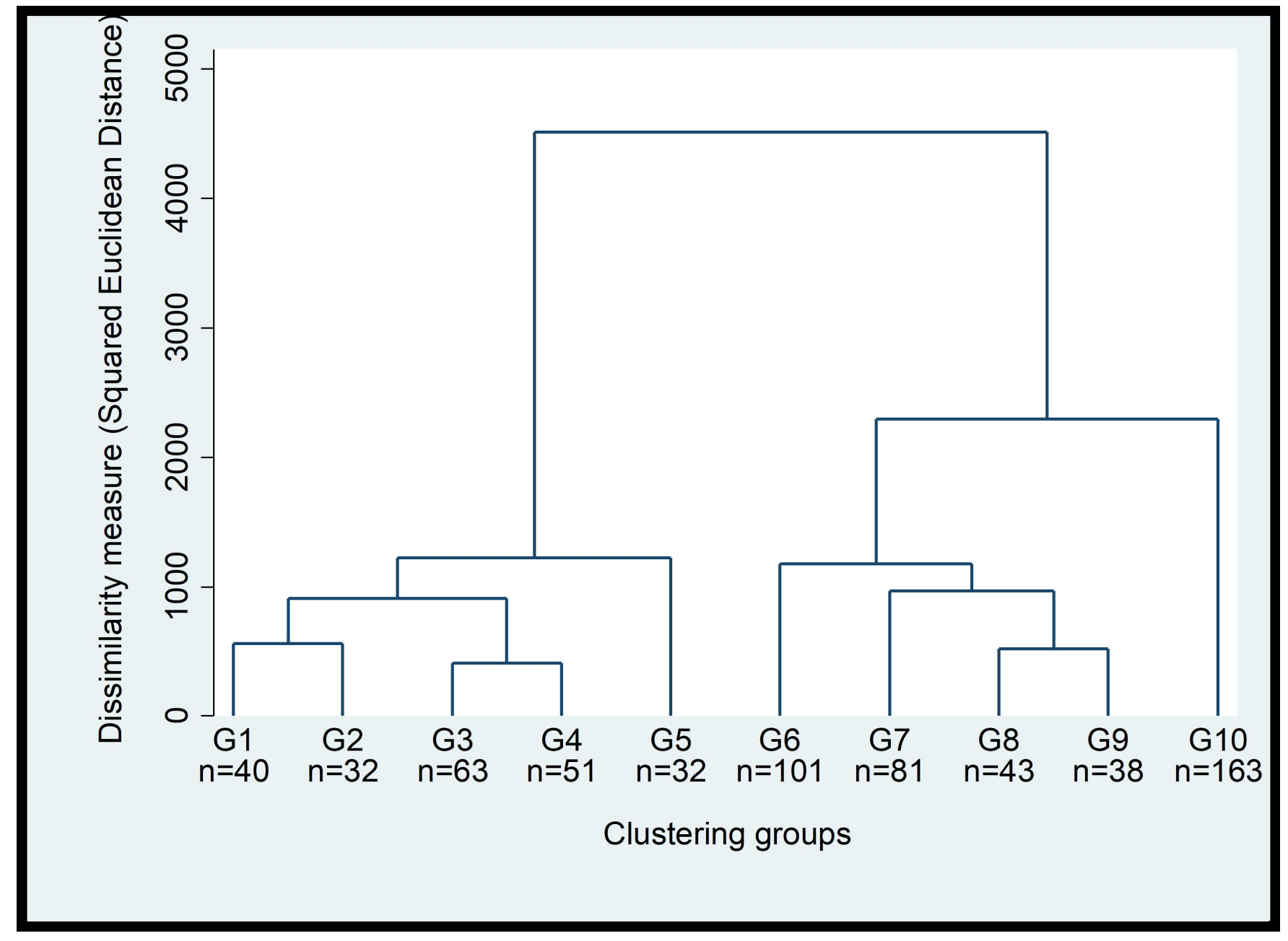

Figure Appendix.3: Cluster Dendogram 


\begin{tabular}{c|c|c}
\hline No. of clusters & $\mathrm{Je}(2) / \mathrm{Je}(1)$ & $T^{2}$ \\
\hline 1 & 0.7428 & 222.27 \\
2 & 0.6774 & 201.91 \\
3 & 0.7924 & 56.61 \\
\hline 4 & 0.7288 & 97.15 \\
5 & 0.6670 & 79.89 \\
6 & 0.7752 & 53.36 \\
7 & 0.5329 & 61.35 \\
8 & 0.6347 & 45.47 \\
9 & 0.7878 & 30.17 \\
10 & 0.8094 & 14.36 \\
\hline
\end{tabular}

Table B1: Duda Hart criteria

\begin{tabular}{c|c}
\hline No. of clusters & Calinski/Harabasz pseudo-F \\
\hline 2 & 222.27 \\
3 & 203.28 \\
\hline 4 & 180.32 \\
5 & 176.74 \\
6 & 176.47 \\
7 & 182.63 \\
8 & 179.92 \\
9 & 180.08 \\
10 & 178.98 \\
11 & 172.77 \\
\hline
\end{tabular}

Table B2: Using Calinkski/Harabasz pseudo F values

\section{Appendix C: Description of variables and further results for the extended MNL model}

\begin{tabular}{l|cccccc}
\hline & Travel time & Travel cost & Coordination effort & Age & Income & Male \\
\hline Travel time & 1.00 & & & & & \\
Travel cost & $-0.11^{*}$ & 1.00 & & & & \\
Coordination effort & $0.14^{*}$ & $0.16^{*}$ & 1.00 & & & \\
Age & -0.01 & -0.01 & $-0.04^{*}$ & 1.00 & & \\
Income & $0.05^{*}$ & $0.05^{*}$ & -0.02 & $0.05^{*}$ & 1.00 & \\
Male & 0.00 & 0.00 & $-0.07^{*}$ & $0.28^{*}$ & $0.12^{*}$ & 1.00 \\
\hline
\end{tabular}

Table C1: Correlation Matrix 


\begin{tabular}{|c|c|c|c|c|}
\hline Variable & Modes & Bicycle & Walking & Pub.Trans. \\
\hline Age & & $\begin{array}{l}-0.137 \\
(0.217)\end{array}$ & $\begin{array}{l}-0.319 \\
(0.303)\end{array}$ & $\begin{array}{l}0.0895 \\
(0.203)\end{array}$ \\
\hline Income & & $\begin{array}{c}-0.709^{* * *} \\
(0.269)\end{array}$ & $\begin{array}{l}-0.491 \\
(0.333)\end{array}$ & $\begin{array}{c}-0.767^{* * *} \\
(0.235)\end{array}$ \\
\hline Gender & & $\begin{array}{c}0.135 \\
(0.607)\end{array}$ & $\begin{array}{l}-0.114 \\
(0.730)\end{array}$ & $\begin{array}{l}-0.697 \\
(0.564)\end{array}$ \\
\hline Pub trans. lovers & & $\begin{array}{c}2.307^{* * *} \\
(0.844)\end{array}$ & $\begin{array}{c}0.718 \\
(0.939)\end{array}$ & $\begin{array}{c}1.196 \\
(0.769)\end{array}$ \\
\hline Car lovers & & $\begin{array}{c}-2.915^{* * *} \\
(0.789)\end{array}$ & $\begin{array}{c}-19.43^{* * *} \\
(0.994)\end{array}$ & $\begin{array}{c}-5.278^{* * *} \\
(0.686)\end{array}$ \\
\hline Family size & & $\begin{array}{c}0.380 \\
(0.454)\end{array}$ & $\begin{array}{c}0.331 \\
(0.554)\end{array}$ & $\begin{array}{c}0.554 \\
(0.421)\end{array}$ \\
\hline Education & & $\begin{array}{c}0.136 \\
(0.282)\end{array}$ & $\begin{array}{c}0.155 \\
(0.375)\end{array}$ & $\begin{array}{c}0.293 \\
(0.247)\end{array}$ \\
\hline Employment & & $\begin{array}{l}-0.603 \\
(0.897)\end{array}$ & $\begin{array}{l}-0.189 \\
(1.065)\end{array}$ & $\begin{array}{l}-0.285 \\
(0.984)\end{array}$ \\
\hline Travel time & $\begin{array}{c}-4.097^{* * *} \\
(0.990)\end{array}$ & & & \\
\hline Travel cost & $\begin{array}{c}-0.615^{*} \\
(0.353)\end{array}$ & & & \\
\hline Coordination effort & $\begin{array}{c}-0.430 * * * \\
(0.145)\end{array}$ & & & \\
\hline Constant & & $\begin{array}{c}3.332^{* *} \\
(1.633)\end{array}$ & $\begin{array}{c}6.328^{* * *} \\
(2.049)\end{array}$ & $\begin{array}{c}3.846^{* * *} \\
(1.396)\end{array}$ \\
\hline Observations & 1148 & 1148 & 1148 & 1148 \\
\hline Log likelihood & -184.97 & -184.97 & -184.97 & -184.97 \\
\hline No. of individuals & 359 & 359 & 359 & 359 \\
\hline
\end{tabular}

Note: Dependent variable is the means of transport that people use to get from their place of residence to the leisure event. Multinomial logit model is used. Base outcome is car driving. Robust SE are reported in parentheses.

Table C2: Mode choice decisions while going to work (controlling for other socio-economic characteristics 


\begin{tabular}{|c|c|c|c|c|}
\hline Variable & Modes & Bicycle & Walking & Pub.Trans. \\
\hline \multirow[t]{2}{*}{ Age } & & -0.187 & $-0.576^{* *}$ & 0.111 \\
\hline & & $(0.233)$ & $(0.287)$ & $(0.184)$ \\
\hline \multirow[t]{2}{*}{ Income } & & $-0.616^{* *}$ & -0.00789 & $-0.534^{* *}$ \\
\hline & & $(0.259)$ & $(0.316)$ & $(0.216)$ \\
\hline \multirow[t]{2}{*}{ Gender } & & 0.295 & -0.0582 & -0.585 \\
\hline & & $(0.627)$ & $(0.909)$ & $(0.575)$ \\
\hline \multirow[t]{2}{*}{ Pub trans. lovers } & & $2.612^{* * *}$ & 1.549 & 1.073 \\
\hline & & $(1.007)$ & $(1.051)$ & $(0.936)$ \\
\hline \multirow[t]{2}{*}{ Car lovers } & & $-2.399 * * *$ & $-17.13^{* * *}$ & $-4.882^{* * *}$ \\
\hline & & $(0.841)$ & $(0.903)$ & $(0.753)$ \\
\hline \multirow[t]{2}{*}{ Residence in countryside } & & $-14.25 * * *$ & $2.732^{* *}$ & 0.809 \\
\hline & & $(1.403)$ & $(1.385)$ & $(1.266)$ \\
\hline \multirow{2}{*}{ Residence in suburbs } & & 0.00752 & 0.0627 & -0.0749 \\
\hline & & $(0.831)$ & $(1.071)$ & $(0.744)$ \\
\hline \multirow[t]{2}{*}{ Residence in small city } & & -0.671 & 0.783 & -0.837 \\
\hline & & $(1.196)$ & $(1.824)$ & $(1.168)$ \\
\hline \multirow[t]{2}{*}{ Residence in medium city } & & -0.275 & 0.514 & $-1.793^{*}$ \\
\hline & & $(0.879)$ & $(0.976)$ & $(0.921)$ \\
\hline \multirow[t]{2}{*}{ Time to pub trans. from residence } & & -0.401 & 0.0149 & -0.343 \\
\hline & & $(0.470)$ & $(0.746)$ & $(0.476)$ \\
\hline \multirow[t]{2}{*}{ Time to pub trans. from work } & & 0.0732 & -0.399 & 0.354 \\
\hline & & $(0.387)$ & $(0.568)$ & $(0.365)$ \\
\hline \multirow[t]{2}{*}{ Freq. of pub trans. connections } & & 0.886 & 1.052 & 0.0135 \\
\hline & & $(0.571)$ & $(0.663)$ & $(0.348)$ \\
\hline \multirow[t]{2}{*}{ Difficulty in parking } & & 0.154 & 0.483 & 0.849 \\
\hline & & $(0.662)$ & $(0.860)$ & $(0.646)$ \\
\hline \multirow[t]{2}{*}{ Ownership of car } & & $-1.411^{*}$ & $-2.620 * * *$ & $-2.140 * * *$ \\
\hline & & $(0.846)$ & $(0.980)$ & $(0.735)$ \\
\hline \multirow[t]{2}{*}{ Travel time } & $-3.678 * * *$ & & & \\
\hline & $(0.930)$ & & & \\
\hline \multirow[t]{2}{*}{ Travel cost } & $-0.639^{*}$ & & & \\
\hline & $(0.367)$ & & & \\
\hline \multirow[t]{2}{*}{ Coordination effort } & $-0.477^{* * *}$ & & & \\
\hline & $(0.162)$ & & & \\
\hline \multirow[t]{2}{*}{ Constant } & & 1.089 & 2.889 & $5.736^{* *}$ \\
\hline & & $(3.087)$ & $(3.796)$ & $(2.580)$ \\
\hline Observations & 987 & 987 & 987 & 987 \\
\hline Log likelihood & -142.01 & -142.01 & -142.01 & -142.01 \\
\hline No. of individuals & 304 & 304 & 304 & 304 \\
\hline
\end{tabular}

Note: Dependent variable is the means of transport that people use to get from their place of residence to the leisure event. Multinomial logit model is used. Base outcome is car driving. Robust SE are reported in parentheses.

Table C3: Mode choice decisions while going to work ( 8 gitrolling for residence and workplace characteristics and the access to infrastructure 


\begin{tabular}{|c|c|c|c|c|}
\hline Variable & Modes & Bicycle & Walking & Pub.Trans. \\
\hline Age & & $\begin{array}{l}-0.145 \\
(0.186)\end{array}$ & $\begin{array}{c}-0.332 \\
(0.300)\end{array}$ & $\begin{array}{l}0.0445 \\
(0.103)\end{array}$ \\
\hline Income & & $\begin{array}{c}0.166 \\
(0.206)\end{array}$ & $\begin{array}{l}-0.374 \\
(0.383)\end{array}$ & $\begin{array}{c}0.001 \\
(0.115)\end{array}$ \\
\hline Gender & & $\begin{array}{c}0.187 \\
(0.527)\end{array}$ & $\begin{array}{c}-0.423 \\
(0.819)\end{array}$ & $\begin{array}{l}-0.116 \\
(0.298)\end{array}$ \\
\hline Pub trans. lovers & & $\begin{array}{l}-0.101 \\
(0.605)\end{array}$ & $\begin{array}{l}-1.152 \\
(1.199)\end{array}$ & $\begin{array}{c}0.349 \\
(0.368)\end{array}$ \\
\hline Car lovers & & $\begin{array}{c}-2.148^{* *} \\
(0.970)\end{array}$ & $\begin{array}{l}-0.607 \\
(1.151)\end{array}$ & $\begin{array}{c}-0.983^{* * *} \\
(0.341)\end{array}$ \\
\hline Travel time & $\begin{array}{c}-9.548^{* * *} \\
(2.872)\end{array}$ & & & \\
\hline Travel cost & $\begin{array}{c}-1.818^{* *} \\
(0.741)\end{array}$ & & & \\
\hline Coordination effort & $\begin{array}{c}-0.593^{* * *} \\
(0.118)\end{array}$ & & & \\
\hline Constant & & $\begin{array}{c}1.055 \\
(0.970)\end{array}$ & $\begin{array}{c}6.222^{* * *} \\
(1.961)\end{array}$ & $\begin{array}{c}2.242^{* * *} \\
(0.633)\end{array}$ \\
\hline Observations & 1079 & 1079 & 1079 & 1079 \\
\hline Log likelihood & -224.14 & -224.14 & -224.14 & -224.14 \\
\hline No. of individuals & 370 & 370 & 370 & 370 \\
\hline
\end{tabular}

Note: Dependent variable is the means of transport that people use to get from their place of residence to the leisure event. Multinomial logit model is used. Base outcome is car driving. Robust standard errors are reported in parentheses. ${ }^{*}, * *, * * *$ represent that the estimates are significant at $10 \%, 5 \%$ and $1 \%$ levels of significance respectively.

Table C4: Mode choice decisions while going to the leisure event 


\section{Appendix D: Questions of the survey}

${ }_{511}$ Dear Reviewer, please click on the Supplementary Material below. In the final manuscript, the 512 survey questions will be directly included here. 